\title{
Land-Subsidence and Ground-Water Storage Monitoring in the Tucson Active Management Area, Arizona
}

The Tucson Active Management Area (TAMA) comprises two basins-Tucson Basin and Avra Valley. The TAMA has been directed by Arizona ground-water law to attain an annual balance between groundwater withdrawals and recharge by the year 2025. This balance is defined by the statute as "safe yield." Current ground-water withdrawals exceed recharge, resulting in conditions of ground-water overdraft, which causes removal of water from ground-water storage and subsidence of the land surface. Depletion of storage and associated land subsidence will not be halted until all discharge from the system, both natural and human induced, is balanced by recharge.

The amount of the ground-water overdraft has been difficult to estimate until recently because it could not be directly measured. Overdraft has been estimated using indirect water-budget methods that rely on uncertain estimates of recharge. As a result, the status of the ground-water budget could not be known with great certainty.

Gravity methods offer a means to directly measure ground-water overdraft through measurement of changes in the gravitational field of the Earth that are caused by changes in the amount of water stored in the subsurface. Changes in vertical position also affect the measured gravity value and thus subsidence also must be monitored. The combination of periodic observations of gravity and vertical positions provide direct measures of changes in stored ground water and land subsidence.

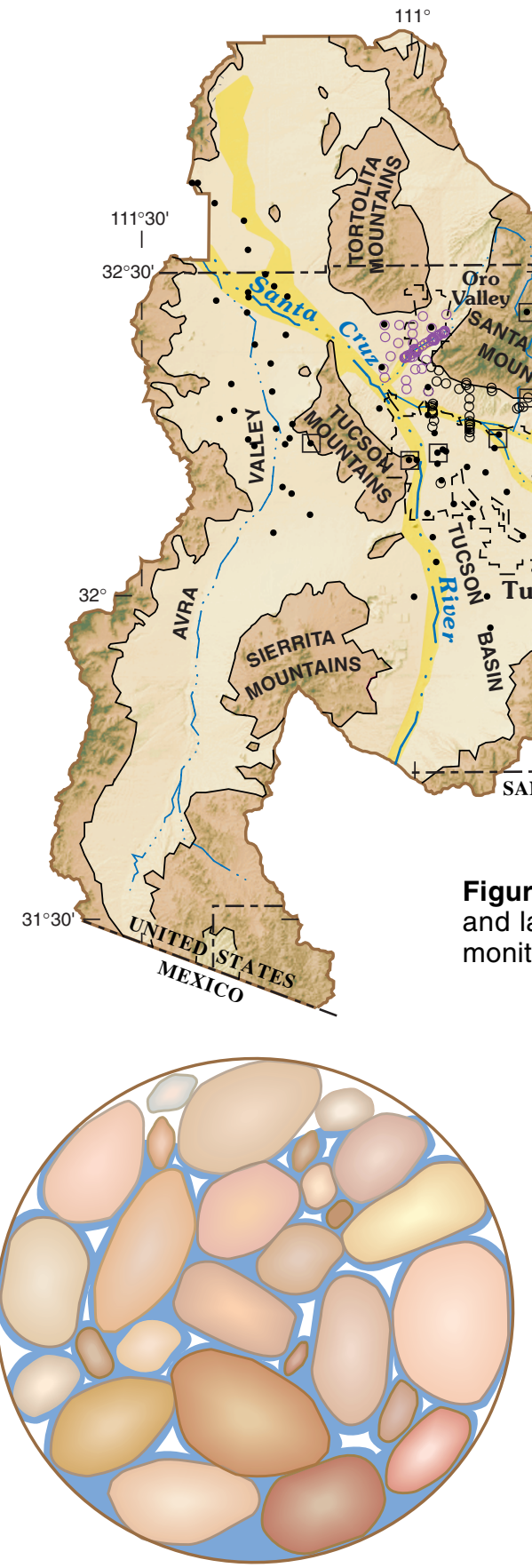

Figure 2. Saturated, partially saturated, and dry spaces between grains of sediment.

\section{Ground-Water Storage}

Ground water in the TAMA (fig. 1) is stored in the pore spaces between grains of sediment in the subsurface (fig. 2). Some pore spaces are filled with water and others are dry or partially filled with water. The amount of ground water that is stored in the TAMA changes as pores drain or fill with water and compact or expand as water levels in the aquifer fall and rise. Under current conditions of overdraft, ground water is derived from two storage sources-drainage of pore spaces between grains of sediment and reduction in pore volume in compressible parts of the aquifer system. 
Sediments that contain a significant amount of silt and clay are the most compressible. Declining water levels result in compaction of pore spaces and subsidence of the land surface.

Losses in ground-water storage in the TAMA have been difficult to estimate using previously existing methods. Storage loss that results from pore-space compaction across the upper part of the aquifer system is monitored at 14 vertical extensometers in the TAMA, but extensive areal surveys, which are required to measure compaction of the entire aquifer, have not been done on a routine basis. Storage loss that is caused by drainage of pore spaces also has not been monitored. Pore-space drainage can be estimated indirectly by multiplying estimated specific yield of the aquifer and water-level decline in wells. The specific yield of the aquifer is the amount of water that is released from storage per unit decline in the water table. The specific-yield method requires knowledge of: (1) specific yield and (2) change in position of the water table. This information is rarely available over large areas for aquifers in the Southwest. Values of specific yield can be determined, but long-term and costly tests are required. Values estimated from the tests are only applicable to the small volume of aquifer that was tested. Futhermore, water-level changes in deep wells seldom reflect changes in the position of the water table because water levels vary with depth in alluvial aquifers of the Southwest. Most wells in the TAMA probably do not have water levels that are representative of the water table because the wells derive water from multiple deep aquifers. Monitoring of land subsidence using the Global Positioning System (GPS) and monitoring drainage of pore spaces using gravity methods will provide direct measurement of the total ground-water storage change.

\section{Previous Investigations}

The current investigation builds on previous work done by the University of Arizona (UA) and the National Geodetic Survey (NGS). NGS and John Sumner of the Geosciences Department at the UA began a program during the 1980's to assess the utility of GPS and gravity measurements for regional monitoring of land subsidence and ground-water storage. Their efforts resulted in GPS and gravity surveys of many stations in the
TAMA during the late-1980's (Cole, 1990; Hatch, 1991). In addition, the NGS established two stations in the Santa Catalina Mountains where the absolute value of gravitational acceleration was measured in February 1989. The stations are part of a national absolute-gravity station network (Peter and others, 1991) and serve as local references for gravity surveys in the Tucson area. The current investigation incorporates most of the stations established during the late1980 's by the UA and NGS.

\section{Current Monitoring Program}

Begining in December 1997, the U.S. Geological Survey (USGS) began a 3-year land-subsidence and groundwater storage monitoring program in cooperation with the Arizona Department of Water Resources, City of Tucson, and Pima County. The goal of the program is to measure land subsidence and ground-water storage on an annual basis at a network of monitoring stations throughout the TAMA. The current network includes 75 stations -43 in the Tucson Basin and 32 in Avra Valley (fig.1). In addition, 64 stations are being monitored in the northwestern part of the Tucson Basin in cooperation with the Metropolitan Domestic Water Improvement District and the Town of Oro Valley (Pool, 1999). Information from these programs should result in a better understanding of recharge rates, ground-water overdraft, and the overall status of the water supply in the TAMA. Thirty-seven stations also are being measured on a seasonal

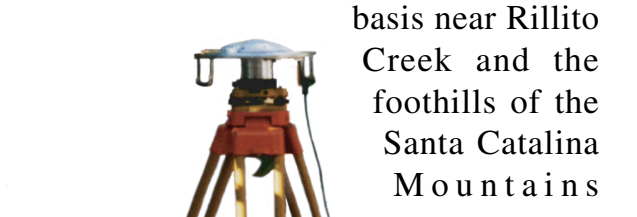

as part of the USGS Southwest GroundWater Resources Program.

\section{Land Subsidence}

Land subsidence is being monitored on an annual basis using GPS equipment. The surveys are done over about 2 to 3 weeks using geodetic GPS receivers; four are operated by Pima County and two are operated by the City of Tucson. Data collected in the field are downloaded to a computer and processed using software that calculates the differential positions among the stations. A network adjustment is done using stations that are located on bedrock as control points with known positions that are assumed not to change. Results of the network adjustments from previous surveys can then be compared to determine changes in position of the stations. Surveyed positions of stations generally are accurate to within about $1 \mathrm{in}$. in the vertical dimension.

\section{Ground-Water Storage}

Changes in ground-water storage are monitored using the gravity method. The method is based on the principles of Newton's Law of Gravitation, which states that the acceleration of gravity within an object's gravitational field is directly related to the mass of the object and inversely related to the square of the distance to the center of the object. In simple terms, an object's gravitational field increases with the mass of the object and decreases with distance from the center of the object. The object that produces the gravitational field in this case is the Earth. Change in the Earth's gravitational field at a location on the surface can be caused by change in the amount of water stored in the subsurface, mass movement in magma and geothermal reservoirs, subsurface faulting, and change in the distance from the center of the Earth. Fortunately, changes in ground-water storage and subsidence are the only likely causes of gravity change in the TAMA.

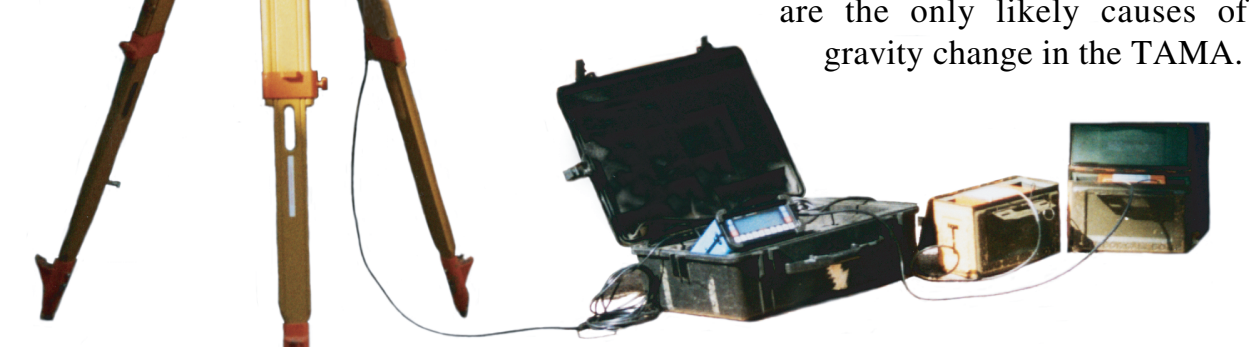

Global Positioning System (GPS) equipment. 
Gravity surveys are done annually at most of the same stations where land subsidence is measured. The relative gravity meter used for this project measures the difference in gravity among stations in the network. Results of the GPS surveys are used to correct the observed gravity change for any change in the vertical positions of stations. Surveys of stations in the Tucson Basin and Avra Valley are completed over a period of about 2 months using several subsurveys of 5 to 8 stations, which include one or more stations in common with another subsurvey. The surveys generally are capable of measuring differences in gravity among stations of about 5 microGal, which is roughly equivalent to the change in gravity resulting from the addition or removal of an extensive layer of water that is about 5 in. thick.

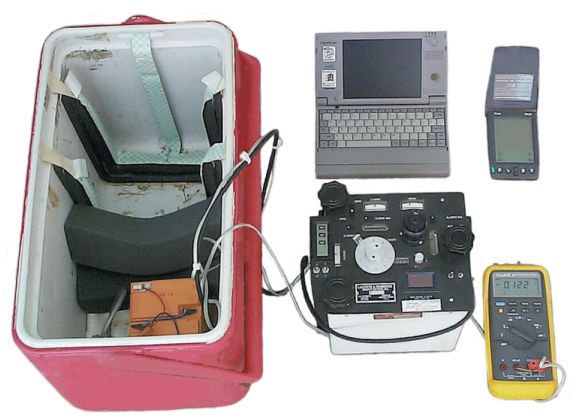

Relative gravity meter.

Use of relative-gravity surveys for the purpose of estimating mass change requires at least one gravity-reference station at which the acceleration of gravity does not change or where changes can be monitored. Because of this need, the monitoring network includes stations in bedrock areas surrounding the TAMA at which gravity is expected to vary little. Any change that occurs at the bedrock stations will result in an inaccurate assessment of mass change throughout the network. Annual measurements of the absolute value of gravitational acceleration are, therefore, done at 6 stations in the network- 4 of the absolute-gravity stations are on bedrock and 2 overlie aquifers. The relative-gravity surveys are corrected for changes that occur at the absolute-gravity stations.

The absolute-gravity measurements are done by the NGS using a falling-mass gravity meter. Current measurements are accurate to within about \pm 2 microGal, which is equivalent to the gravity change resulting from the addition or removal of an extensive layer of water that is about 2 in. thick.

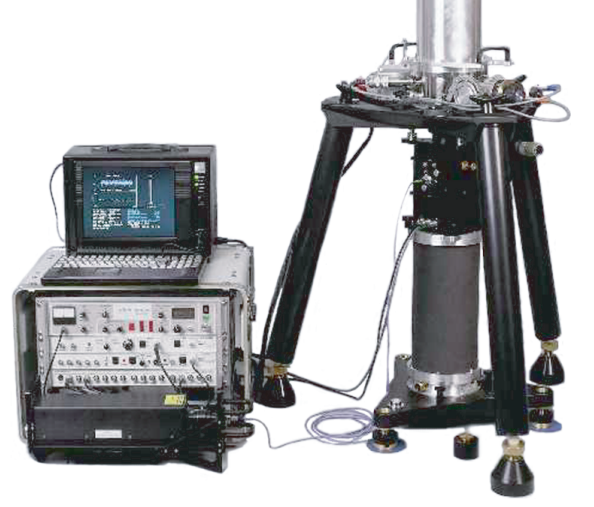

Absolute gravity meter.

\section{Results, 1987-98}

Results of the 1998 surveys were compared with results of the surveys completed during the late-1980's. The 1998 survey included 31 subsidencemonitoring stations surveyed during 1987 by NGS in the Tucson Basin and Avra Valley (Schumann and Anderson, 1988), and 22 ground-water storage monitoring stations surveyed in the Tucson Basin during 1989 by the UA. The 1989 surveys did not include ground-water storage monitoring stations in Avra Valley. Many stations that were surveyed during the late-1980's have been destroyed by construction activities and could not be resurveyed.

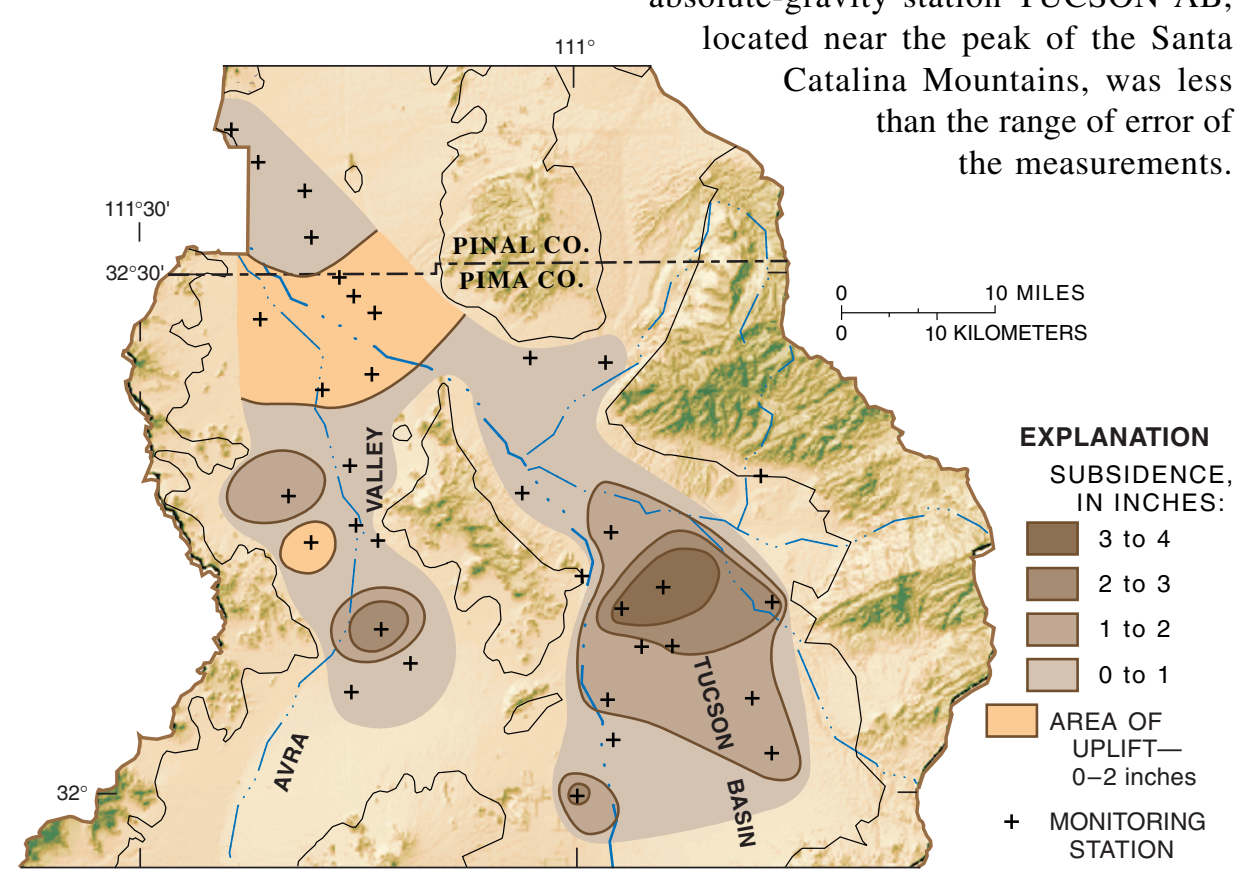

Figure 3. Land-subsidence in the Tucson Basin and Avra Valley, 1987-98.

Land subsidence from 1987 to 1998 was greater in the Tucson Basin than in Avra Valley (fig. 3). Most of the stations in the Tucson Basin subsided by 1 in. or more and the maximum subsidence of about 4 in. occurred in the central part of the basin. Subsidence in Avra Valley generally was less than 1 in., but several stations in the northern part of the valley displayed uplift of as much as $2 \mathrm{in}$. Maximum subsidence of 2 to $3 \mathrm{in}$. occurred in the south-central part of Avra Valley.

\section{Ground-Water Storage}

Ground-water storage losses occurred throughout most of the Tucson Basin from 1989 to 1998 (fig. 4). Storage change is expressed as an equivalent thickness of water that would result in the measured change in gravity. Losses of more than $2 \mathrm{ft}$ of water occurred in the north-central part of the basin and included a maximum loss of more than 6 $\mathrm{ft}$ of water. Increases in storage of nearly $3 \mathrm{ft}$ of water occurred in sediments near the mountains along the north, east, and south margins of the basin, which resulted in increases in gravity at station POST and absolute-gravity station TUCSON AA that were equivalent to $1.6 \mathrm{ft}$ and $0.5 \mathrm{ft}$ of water respectively. These stations are on bedrock near the basin margin (fig. 4). Gravity change equivalent to $-0.1 \mathrm{ft}$ of water at the absolute-gravity station TUCSON AB, Catan meak of the Santa na Mountains, was less the measurements. 


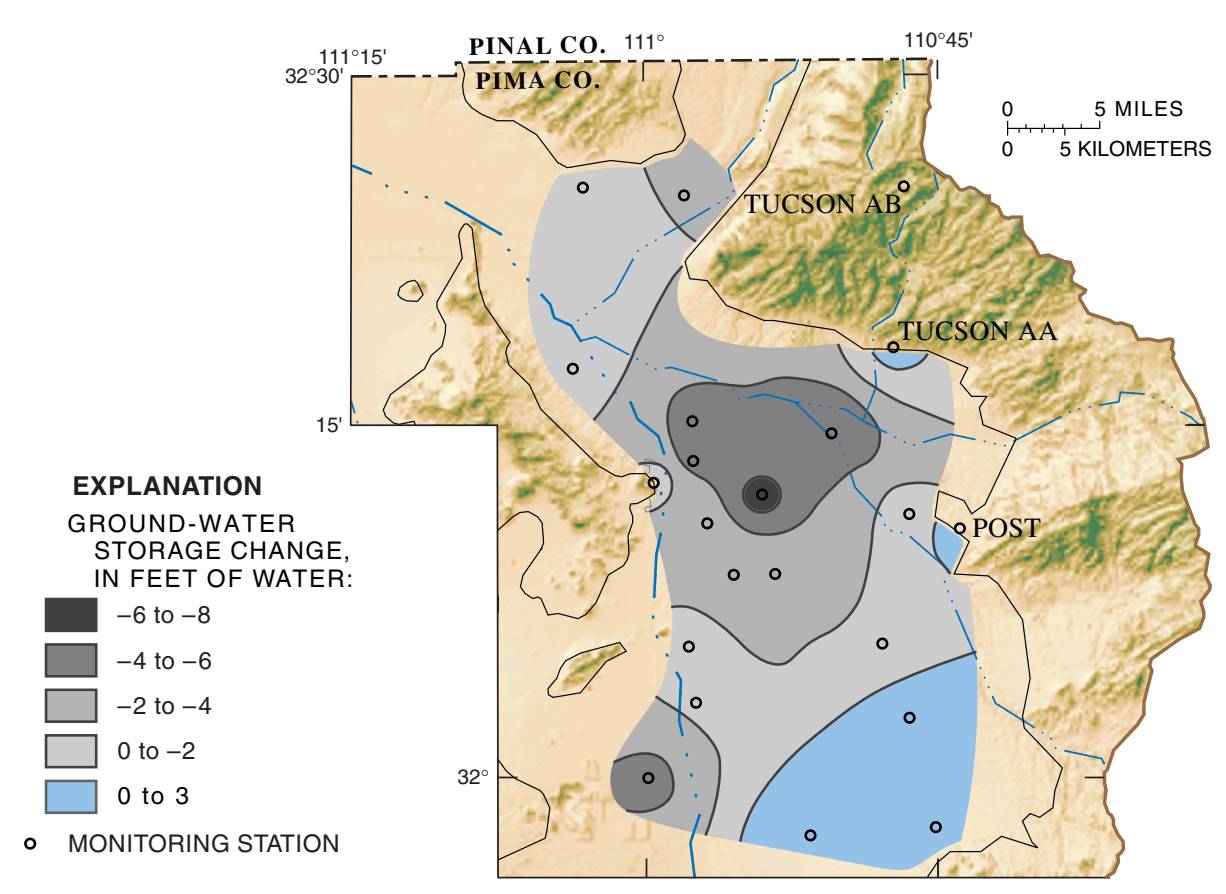

Figure 4. Ground-water storage change in the Tucson Basin, 1989-98.

A point worth noting is that because the aquifer includes both solids and void spaces, change in position of the water table is much greater than the storage change expressed as an equivalent thickness of water. For example, assuming a specific yield of 0.02 , a thickness of water storage loss of $1 \mathrm{ft}$ might reflect a decline in the water table of $5 \mathrm{ft}$ or more.

\section{Water Levels}

Changes in water levels in wells in the Tucson Basin from 1989 to 1998 (fig. 5, City of Tucson, unpublished data) generally compare favorably to groundwater storage change. Water levels declined throughout most of the basin. The maximum water-level decline of greater than $40 \mathrm{ft}$ occurred in the north-central part of the basin near the area of maximum loss in ground-water storage. More than $40 \mathrm{ft}$ of decline also occurred near the southeast extent of the Tucson Mountains in an area lacking storage-monitoring stations. More than $10 \mathrm{ft}$ of water-level decline occurred in two areas near the south and north margins of the basin. Water levels rose near the north and east

margins of the basin, consistent with increased ground-water storage near stations TUCSON AA and POST. Water-level data were not available for the south margin of the basin to compare to measured increases in storage.

\section{Future Monitoring Program}

Monitoring of land subsidence and ground-water storage in the TAMA will continue to provide water managers with valuable information in the future. The monitoring schedule probably will be modified to accomodate changing technology and data needs. Advancing technology in the measurement of the Earth's gravitational field should allow more accurate and more frequent measurement of the absolute value of gravity at more monitoring stations. The existing network of monitoring stations provides control for additional investigations of land subsidence and groundwater storage change near wells and areas where natural and artificial recharge occurs. More detailed knowledge of the seasonal and areal distributions of changes will allow better evaluation of changes that are observed over periods of a year or more.

\section{-D.R. Pool (USGS), Daniel Winster} (National Oceanic and Atmospheric Administration National Geodetic Survey), and K.C. Cole (Grand Valley State University)

\section{References Cited}

Cole, K.C., 1990, Estimation of mass flux and aquifer properties using global-positioning system and microgravity in the Tucson Basin, southern Arizona: Tucson, University of Arizona doctoral dissertation, $193 \mathrm{p}$.

Hatch, M.A., 1991, Global positioning system measurement of subsidence in the Tucson Basin, Pima County, Arizona: Tucson, University of Arizona doctoral dissertation, $71 \mathrm{p}$.

Peter, G., Klopping, F.J., Carter, W.E., and Dewhurst, W.T., 1991, Absolute gravity reference sites in the United States: The Leading Edge, Society of Exploration Geophysics, v. 10, no. 7, p. 43-45.

Pool, D.R., 1999, Aquifer-storage change in the Lower Cañada del Oro subbasin, Pima County, Arizona, 1996-98: U.S. Geological Survey Water-Resources Investigations Report 99-4067, 3 sheets.

Schumann, H.H., and Anderson, S.R., 1988, Landsubsidence measurements and aquifer-compaction monitoring in Tucson Basin and Avra Valley, Arizona: U.S. Geological Survey Water-Resources Investigations Report 88-4167, 15 p.

For further information contact:

Don R. Pool

U.S. Geological Survey, WRD 520 N. Park Avenue, Suite 221 Tucson, Arizona 85719-5035

E-mail: drpool@usgs.gov or visit home page http://az.water.usgs.gov 